\title{
WORK RELEASE IN NORTH CAROLINA- A PROGRAM THAT WORKS!
}

\author{
ANN D. WITTE*
}

\section{INTRODUCTION}

On an average day more than fourteen hundred inmates of North Carolina prisons leave their cells to work in regular jobs in the private sector. This work release program, the largest and oldest of its kind ${ }^{1}$ in the nation, saves the state a substantial amount of money and provides inmates with an opportunity to gain valuable work experience while supporting their dependents and saving money towards the day of their release. My study of the post-release criminal activities of North Carolina prisoners demonstrates that this program provides an additional benefit: it has the effect of reducing the propensity of releasees to commit serious crimes. This finding serves as a rebuttal to the claim that "nothing works" in the field of criminal rehabilitation. Something does work, and, fortuitously, it is a program that is generally compatible with other objectives of the criminal justice system, including incapacitation, deterrence, and reasonable criminal justice system budgets.

The last few years have seen an aura of self-doubt and questioning pervade this country's correctional system. Previously this system was selfconfident in its mission to rehabilitate offenders. The correctional system under the rehabilitative philosophy saw criminal offenders as "sick" people who were to be cured through treatment. Correctional treatment took the form of a variety of rehabilitative programs.

Three developments since the early 1960 s have contributed to the recent questioning. First, a substantial body of empirical literature emerged which seemed to indicate that deterrence works. ${ }^{2}$ These findings found a theoretical justification with the emergence of the economic model of crime in the late 1960s. Second, a large number of rehabilitative program evaluations appeared

\footnotetext{
* Assistant Professor of Economics, University of North Carolina.

1. North Carolina's program is state-wide and state administered and includes misdemeanants and felons. California's program is county option for misdemeanants. Both were established in 1957. W.H. Busher has extensively described the programs and enabling legislation. W. Busher. Work Release: A Compilation of Enabling Legislation (1972) (American Justice Institute mimeo); W. Busher, Ordering Time to Serve Prisoners: A Manual for the Planning and AdminISTRATION OF WORK RELEASE (1973).

2. Philip Cook provides a review of this literature in this issue. Cook, Punishment and Crime. A Critique of Current Findings Concerning the Preventive Effects of Punishment, 41 LAw \& Contemp. ProB. no. I, at 164 (1977).
} 
which indicated that "with few and isolated exceptions, the rehabilitative efforts that have been reported so far have had no appreciable effect on recidivism."3 Finally came the emergence of the current civil liberties movement in corrections. ${ }^{4}$ Members of this movement actively defended offenders' rights not to be rehabilitated, and pointed to numerous injustices which had occurred in the name of rehabilitation.

These developments have led many correctional agencies to the rejection of rehabilitation as a viable goal. Indeed, even the Federal Bureau of Prisons, which was one of the most active proponents of rehabilitation in the $1960 \mathrm{~s}$, has recently given up both the notion that there is a cure for crime, and the idea that rehabilitation is the main reason for incarceration. ${ }^{5}$

The critics of rehabilitation offer conflicting advice. One group of critics, coming mainly from the civil liberties movement, suggests that we should close prisons because rehabilitation is possible only outside prison walls. Recently a former head of the Massachusetts prison system took this advice, but before he could close many of that State's prisons he was fired because of adverse public reaction. The second group of critics, most of whom concentrate on the rising crime rate, seems more attuned to current public attitudes. These critics suggest that we maintain and perhaps even expand prisons. They maintain, however, that prisons should have few if any rehabilitative programs, and that they should emphasize deterrence and incapacitation as their primary goals.

This rejection of rehabilitation not only seems premature but also constitutes a Hegelian swing of correctional philosophy toward incapacitation and deterrence that for a number of reasons would be ill-conceived at this time. The empirical work which purports to show that deterrence does work is susceptible to serious criticism because of both the nature of the data and the methodologies used. ${ }^{6}$ Further, although the economic model of crime indicates that deterrence should work, it also points out that improved legitimate opportunities should lower participation in crime. In this connection, a third point becomes important. The vast majority of rehabilitative program evaluations have dealt with programs that seek to change the personality of the criminal offender with psychological or psychiatric techniques. An alternative rehabilitative philosophy which seeks to change not the personality of an offender but rather the opportunities facing him was little used in the $1960 \mathrm{~s}$,

3. Martinson, What Works? Questions and Answers about Prison Reform, 25 PUB. INTERest 35 (Spring 1974).

4. The work of Norval Morris is an excellent example. See generally N. Morris, The Future OF IMPRISONMENT (1974).

5. Federal Bureau of Prisons Chief Norman Carlson, in Carlson, Giving up the Medical Model?, 6 Behavior Today 679 (1975).

6. Nagin, General Deterrence: A Review of the Empirical Evidence, in Management Science (forthcoming). 
and when this approach was used it was rarely evaluated. ${ }^{7}$ In 1972 , Robert Taggart commented: "Experience with manpower programs for offenders is limited. There is no rigorous proof that any strategy is effective, or that all of these together can have significant impact."8 Manpower programs would find support in the economic model of crime.

Since 1972, experience with manpower programs for criminal offenders has increased and a number of evaluations have appeared which give at least some cause for optimism. The results of one such evaluation are described in detail below. The first section describes the North Carolina work release program and its benefits. The second section describes the methods used in the evaluation. Section three reports the results of the evaluation and the final section summarizes the paper and draws conclusions.

1

\section{North Carolina's Work Release Program}

\section{A. The Benefits}

North Carolina has one of the oldest and largest work release programs in the United States. This program allows inmates to leave prison each day to work at normal jobs in the community. The North Carolina program expanded from eight inmates in its first two years (July 1, 1957 to July 1, 1959) to a daily average in fiscal year 1975 of more than fourteen hundred, approximately 11 per cent of the North Carolina prison population.

To the legislators who established and later expanded this work release program, one of its greatest attractions was that it benefits the state financially in a number of ways. A person on work release reimburses the Department of Correction for his room and board and for transportation to and from his place of employment. He also makes payments to his dependents, thus saving the state welfare expenditures. Finally he pays state and federal income taxes.

These financial benefits have proven to be substantial. Between 1957 , when the program was established, and the end of fiscal year 1972, the Department of Correction received more than $\$ 7$ million for room and board and approximately $\$ 2$ million for transportation. In addition, work releasees during this period paid approximately $\$ 7$ million to their dependents. In fiscal year 1975 alone, not a particularly good year for work release due to the general recession, the department received over $\$ 1$ million for room and board and approximately $\$ 110,000$ for transportation. Welfare payments by work releasees in that year were almost $\$ 2$ million. Taxes paid are impossible

7. This distinction between personality changing and opportunity changing approaches was suggested to me by Philip Cook. See Cook, The Correctional Carrot: Better Jobs for Parolees, 1 PoL'Y ANALYSIS 11 (1975).

8. Taggart, Manpower Programs for Criminal Offenders, 22 Monthly LAB. Rev. 17-24, 95 (1972). 
to ascertain directly from the returns but are estimated to have been more than $\$ 330,000$ in fiscal year 1975.4 The total of all these payments average between five and six per cent of state expenditures on corrections in North Carolina. Taking into consideration these and other benefits, and reducing estimated benefits by the cost of the work release program, it was estimated that, in 1968, the transfer of one man from prison industries to work release resulted in a $\$ 2,056$ yearly net gain to society. ${ }^{10}$

A second major attraction of the work release program is that it appears to reduce the seriousness of recidivist criminal activity. This reduction will be shown below to be mainly the result of the improved labor market opportunities available to men who have been on the work release program.

A potential drawback of the work release program is that it might neither incapacitate inmates nor deter them and others as effectively as simple imprisonment. There is no objective measure of the effect of work release on either special or general deterrence. However, considering the low quality of work release jobs and the generally unpleasant nature of prison life even with work release, one would expect little dilution of either deterrent effect.

Based on the North Carolina experience, it is possible to estimate the degree to which work release decreases incapacitation. The vast majority $(85$ per cent in 1974) of men who participate in the work release program complete it without escaping or violating the rules governing the program. Six per cent of the men participating in the program in 1974 were removed from it for violations of the rules and nine per cent were removed because they escaped. This nine per cent escape rate is lower than the rate for the prison system as a whole, largely because a man usually must be a low escape risk before he is allowed to participate in the work release program. Of the men who do escape from the work release program, it has been estimated that only 10 per cent are charged with an offense other than escape before their recapture. ${ }^{11}$ Escapes from work release often consist of nothing more than leaving the work release area to go home to straighten out a family problem or to get a drink (many of the men on the work release program are alcoholics).

These rule violations are often very minor incidents because the rules governing the work release program are strictly enforced. One drink, an hour away from the job, or the possession of two dollars in excess of an individual's

9. This estimate was made as follows: Mean hourly wage for the sample while on work release was brought forward to December 1974 using the Consumer Price Index. The hourly wage obtained was multiplied by forty hours and fifty-two weeks to obtain an estimated average annual income in fiscal year 1975 for work releasees. State and federal income taxes on such an income were estimated using the average number of dependents for work releasees in the sample and 1975 tax rates. Sales tax payments were estimated using the 1975 federal tables for state sales tax. Total tax payments were multiplied by the average daily number of men on work release in 1975.

10. W. Cooper, An Economic Analysis of the Work Release Program 50 (1968) (unpublished Ph.D. dissertation at North Carolina State University).

11. Id. at 62 . 
ten dollar expense allowance are significant enough violations to remove a man from the work release program in North Carolina. It is estimated that only 16 per cent of removals for failure to abide by the rules involve illegal acts. ${ }^{12}$ These two sets of facts lead to the conclusion that approximately two per cent of the work releasees placed in the community will be charged with a new offense other than escape. Since some of the escapes, and hence some of the offenses committed on escape, would have occurred even if an individual had not been on work release, the best estimate of new offenses committed due to the existence of a work release program is one to one and one-half per cent of the number of men participating in the program. ${ }^{13}$ For a program like North Carolina's, with approximately four thousand participants each year, the number of criminal offenses is probably increased forty to sixty offenses a year as a result of the program. This estimate assumes no loss in deterrence. Thus, the cost savings and rehabilitative effects of work release must be weighed against this increase in offenses. Although 1 have not formally evaluated the social costs of these offenses nor the rehabilitative effects of work release, I believe that the rehabilitative effects alone would more than outweigh this loss in incapacitation.

\section{B. The Program}

As can be seen in Table 1 , it was most common for men to be placed on work release either prior to serving six months of their terms or after they had served more than a year. This dichotomy in time-served-until-workrelease is a reflection of the fact that both misdemeanants and felons are allowed to participate in the program. Misdemeanants are most likely to be placed on work release after a short time in prison, whereas felons usually participate shortly before their release. The parole board uses work release extensively as a testing ground for parole. Indeed, under the North Carolina work release statute, ${ }^{14}$ inmates with sentences of more than five years are not eligible to participate in the work release program until they have served 15 per cent of their sentence.

Before an individual can be seriously considered for work release, he has to have a job at which he plans to work. In about 65 per cent of the cases, job plans are developed for inmates by prison unit employees. About 30 per cent of the inmates involved develop their own job plans. When an inmate develops his own job plan, he usually returns to the job he had prior to entering prison. In only approximately 10 per cent of the cases are men able to find new jobs for themselves while in prison, partially because there are insuffi-

12. J. Sarratt, Work Release Failure (Aug. 2, 1969) (unpublished memorandum at N.C. Dep't of Correction).

13. This assumes that all charges are valid.

14. N.C. Gen. Stat. \$148-33.1. 
TABLE. I

Time Served Until. Placement on the Work Release Program $(n=297)^{\mathrm{a}}$

\begin{tabular}{lc}
\hline \multicolumn{1}{c}{ Time } & $\begin{array}{c}\text { Relative Frequency } \\
\text { (per cent) }\end{array}$ \\
\hline 1 month or less & 29 \\
1 month, 1 day to 2 months & 22 \\
2 months, 1 day to 6 months & 24 \\
6 months, 1 day to 12 months & 10 \\
over 12 months & 15 \\
& \\
Mean: 7.1 months & 100.0 \\
Standard Deviation: 12 months & \\
Range: .5 to 103 months & \\
\hline
\end{tabular}

a A random sample of men on work release in the South Piedmont area of North Carolina in 1969 or 1971 .

Source: A. Witte, Work Release in North Carolina: An Evaluation of Its Post ReLEASE EFFECTS 19 (1975).

cient prison personnel to accompany inmates to job interviews. Whatever the cause, the fact that relatively few inmates are able to search for and find new jobs means that a valuable opportunity to teach job search skills is largely neglected in the North Carolina program. The job plans of remaining inmates are developed by family, friends and civic groups.

Work release jobs in general require significantly lower skills and pay significantly lower wages than the jobs men have either before entry to prison or after release. The following were typical work release jobs in the summer of 1973: helper with a chicken processor, five days a week, $\$ 1.90$ per hour, with private means of transportation; painter with a decorating firm, five days a week from 8:00 a.m. to 5:30 p.m., $\$ 2.25$ per hour; mill laborer with a lumber company, five days a week from 7:30 a.m. to 4:30 p.m., $\$ 1.70$ per hour, with transportation provided by the Division of Prisons; machine operator with a heavy construction firm, five days a week from 7:00 a.m. to 6:30 p.m., \$2.25 per hour, with transportation provided free by the employer.

In addition, these jobs often shift individuals out of their accustomed occupations. This means that even when work releasees gain new skills, they often cannot use them after release. ${ }^{15}$ In spite of these problems, work release jobs provide a number of benefits. Most importantly, these jobs provide

15. See Witte, Earnings and Jobs of Ex-Offenders: A Case Study, 99 Monthly LaB. Rev. 31-39 (1976), for an extended discussion of these problems. 
money on release. As reflected in Table II, those savings averaged more than $\$ 400$ in 1969 and 1971 . By contrast, men who do not participate in the program have little more than "gate money."16 Further, these jobs are in many cases the first job held for any substantial period of time and hence provide the prisoner with his first opportunity to compile a stable job record ${ }^{17}$ and to develop the "work habit." Work release jobs also allow inmates to support their families while in prison. Finally, keeping and succeeding in a job despite previous failure in the work world should improve an individual's attitude toward himself and toward society.

Once an individual has a job plan, he must be approved for participation in the work release program. If an individual has a sentence of five years or less, the secretary of the North Carolina Department of Correction may grant this approval. If an individual has a sentence of more than five years, parole board approval is required as well.

The major criteria used in deciding whether or not to approve an indi-

TABLE II

Funds Accumlitated White ox Work Release

$(n=269)^{\text {a }}$

\begin{tabular}{lc}
\hline \multicolumn{1}{c}{ Amount } & $\begin{array}{c}\text { Relative Frequency } \\
\text { (per cent) }\end{array}$ \\
\hline$\$ 0-\$ 100$ & 28 \\
$\$ 101-\$ 250$ & 21 \\
$\$ 251-\$ 500$ & 24 \\
$\$ 501-\$ 1000$ & 16 \\
over $\$ 1000$ & 11 \\
& 100.0 \\
Mean: $\$ 427.82$ & \\
Standard Deviation: $\$ 502.43$ & \\
Range: $\$ 0$ to $\$ 3024$ & \\
\hline
\end{tabular}

a A random sample of men on work release in the South Piedmont area of North Carolina in 1969 or 1971 .

Source: Calculated for this article from the data set used to evaluate the North Carolina work release program. See S. Witte, Work Release in North Carolina: An Evaluation of Its Post Release Effects (1975).

16. "Gate money" in North Carolina ranges from nothing (if an individual served two years or less) to twenty-five dollars (if an individual has served fifteen years or more). External savings for released inmates are small to nonexistent. See D. Glasser, The Effectiveness of a Prison and Parole System 319 (1964); G. Pownall, Employment Problems of Released Offenders 182 (1969).

17. Men in the work release sample changed jobs on the average every eleven months prior to entry into the prison system. Thirty-two per cent of these men changed jobs more frequently than every nine months. 
vidual for work release are, in approximate order of importance, as follows: ${ }^{18}$ the first and most important consideration is the nature of the offense for which the applicant is currently incarcerated. Sex and drug offenders are rarely approved for work release. Offenders whose crimes caused considerable societal displeasure are also unlikely to receive approval. Second, the length of sentence and the proportion already served is considered. Individuals with long sentences are rarely approved for work release until six to eight months before release. Third, the previous criminal record of the individual is examined. Individuals with serious and continuous criminal activity in the past will find it difficult to receive work release approval. The fourth factor considered is the behavior of the individual since his incarceration. An individual must have demonstrated his ability to behave and accept responsibility in order to be approved. Work release is used extensively as a reward for "good behavior" in the North Carolina system. Fifth, the appropriateness of the job plan is examined. A job plan is thought appropriate if it uses or improves a man's skills, helps to develop good work habits, and is likely to be maintained on release. As indicated above, many work release jobs do not meet these criteria. Sixth, an individual's family situation is considered. A married man with children to support is more likely to be approved for work release than a single individual. Seventh, an individual's record is examined to see if he has serious addictive or mental health problems. Finally, an individual's previous employment experience is considered. The pre-prison jobs held by men approved for work release tend to have slightly higher wages and require slightly higher skills than the jobs of those not approved. ${ }^{19}$ However men not in the program have more stable prior work records.

This program description makes it obvious that men on work release are not a random sample of the North Carolina prison population. However, with the exception of previous record considerations and drug or alcohol addiction, none of these factors has been shown to be consistently related to postrelease criminal behavior. ${ }^{20}$ Hence, although work releasees would be expected and indeed are found to be significantly different from other prison inmates, many of the differences between the two groups are unlikely to have significant effect on post-release criminal activity. Further, during the 1969 to 1971 period, all prison units in North Carolina were assigned "road quotas."

18. See A. Witte, Work Release in North Carolina: The Program and the Process (1973) for a detailed description of the work release approval process.

19. These differences are not significant. The term "significant" as used in this article indicates that a finding of statistical significance would have been forthcoming if a two-tailed hypothesis test had been conducted at the five per cent level $(\alpha=.05)$.

20. See P. Service, The Recidivisu of Persons Released from facilitifis of the North Carolina Departanet of Corrections During January-July, 1968 (1972) for review of the work on criminal recidivism; A. Witte \& P. Schmidt, Determinants of Criminal Recidivism (1976) for an analysis of various measures of recidivism for the current data set. 
These quotas required each unit, as a matter of first priority, to supply a set number of men to work on the highways of North Carolina. These men received no pay for their labor. Many men who were eligible for work release during this period were not placed on the program but rather were used to fill the road quota. Therefore men on and off work release were not as different in the 1969 and $197 \mathrm{I}$ period as they were after the abolition of the "road quotas" on July 1, 1973.

The experiences of a prison inmate change markedly once he has been placed on work release. Rather than being assigned routine prison activities ${ }^{21}$ (such as kitchen duty or, at various times, unpaid work on the roads or in prison industries), an inmate leaves his unit each morning, proceeds to his job, usually on a prison bus, works all day in the free community, and returns to his prison unit only at night. The work releasee's reintegration into the community begins with his placement on the program rather than abruptly on release from prison.

\section{II}

\section{Methods Used in the Evaluation}

This evaluation sought to answer two questions. First, does participation in the work release program alter criminal activity after release? Second, if work release participation does lower criminal activity, what facets of the program are mainly responsible for this change?

The ideal method for answering these questions would be randomly to select individuals to participate in the work release program. With random selection, one can assume that the only systematic difference (other than program participation) between those who participated in the work program and those who did not would be a result of chance. Further, any systematic difference in behavior between the two groups would be due to the only systematic difference between them, i.e., participation in the work release program. Such random selection for work release was impossible for two reasons. Most importantly, the statute and administrative procedures outlined above ensure that only certain types of individuals will participate in the work release program. Also, random selection at the beginning of the evaluation (June, 1973) would have meant that the results of the evaluation would not have been available for three to five years. (It is generally believed that follow-up studies of released prison inmates must follow their activities for at least three years to determine true patterns of legal and illegal activities.) ${ }^{22}$ As

21. Some inmates not on work release will be participating in various educational and training programs although such opportunities are quite limited in the North Carolina Correctional System. A large part of a non-work release inmate's day, if not assigned routine prison activities or to work on the road, is spent "killing time."

22. See President's Comm'n on Law Enforcement and the Administration of Justice, Task Force Reports, Corrections (1967); 12 D. Mulvihill \& M. Tumin, Crimes of Violence (1969). 
is common with most criminal justice evaluations, long-term funding was not available. Indeed, funding for field work was for a period of only one year.

The solution to this problem was to choose groups of men who had been released at least three years previously, to find them within a year, and to learn what they had been doing since their release. The years 1969 to 1971 were chosen. A random sample of 297 men who were on the work release program in either one of these two years was selected. The next problem was to find another group which, although it had not participated in the work release program, was identical to the first group in every other way. Due to the shortage of time and lack of readily available information, it proved impossible to locate such a totally comparable group. Consequently, I selected a group of 344 men who were in prison in 1969 or 1971, and who did not participate in the work release program but who had no obvious reason for being ineligible for it. ${ }^{23}$

After selecting the persons I wanted to study, the next task was trying to find them. ${ }^{24}$ The only information about them was the data the Department of Correction had obtained while they were in prison. Starting with this information I scoured the earth - often, it seemed, literally. Thanks to the cooperation of some of the men themselves (unfortunately not all), along with police, sheriffs, the highway patrol, parole and probation officers, other state and local officials, utility companies, private employers, and hundreds of other individuals, I was finally able to locate and interview 453 subjects, 71 per cent of the total sample. Interviewing took place between July 1973 and June 1974.

Information obtained about these men's activities spanned an average period of thirty-seven months after their release from prison. The period for which information was obtained ranged from three to seventy-one months, but there was no significant difference between the average follow-up period for work releasees and non-work releasees. Hence, this variation in follow-up period should not affect comparisons between these two groups.

The project made every attempt to compile a complete criminal record both for those who were interviewed and those who were not. This was done by asking for criminal histories in all jurisdictions where there was any reason to believe a man might have resided after his release from prison. A search of

23. The sample excluded men convicted of sex offenses, serious drug offenses, or as public drunks since such individuals were unlikely to be on work-release. The sample was chosen from a single administrative area, the South Piedmont. However, comparison of the characteristics of men in prison in this area with those in medium- and minimum-custody units in other areas of the state reveal few significant differences. See A. Witte, Work Release in North Carolina: An Evaluation of its POST Release Effects (1975) for a detailed comparison and discussion of sampling methods.

24. This may sound easy, but it proved to be very difficult. On the whole, the field of work on this project was almost never dull, almost always difficult and often harrowing. 
the criminal history files of the FBI was conducted ${ }^{25}$ for those men whom the project was unable to locate.

III

The Findings

A. Criminal Activity After Release

Eighty-two per cent of the former work releasees and 78 per cent of the men who had not been in the program were arrested during the period in which the project followed their activities. The majority of these men were

FIGURE 1

Cumulative Per Cent Rearrested After Various Periods of Time

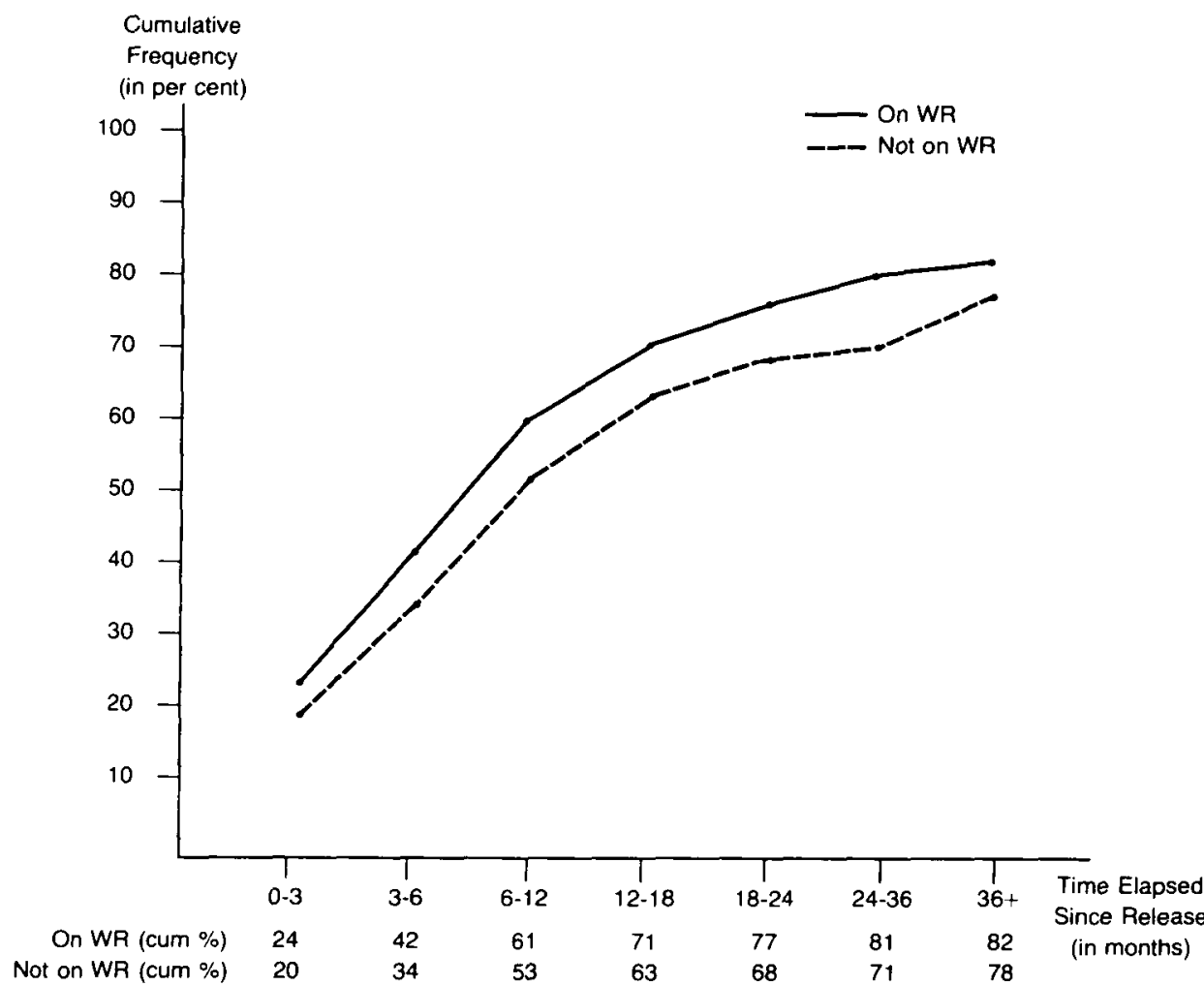

Source: Calculated for this article from the data set used to evaluate the North Carolina work release program. See A. Witte, Work Release in North Carolina: An Evaluation of Its Post Release Effects (1975).

25. For a more detailed description of the methods used and the findings of the evaluation see A. WitTE, supra note 23, at 9-18. 
FIGURE 2

Cumulative Per Cent Reconvicted After Various Periods of Time

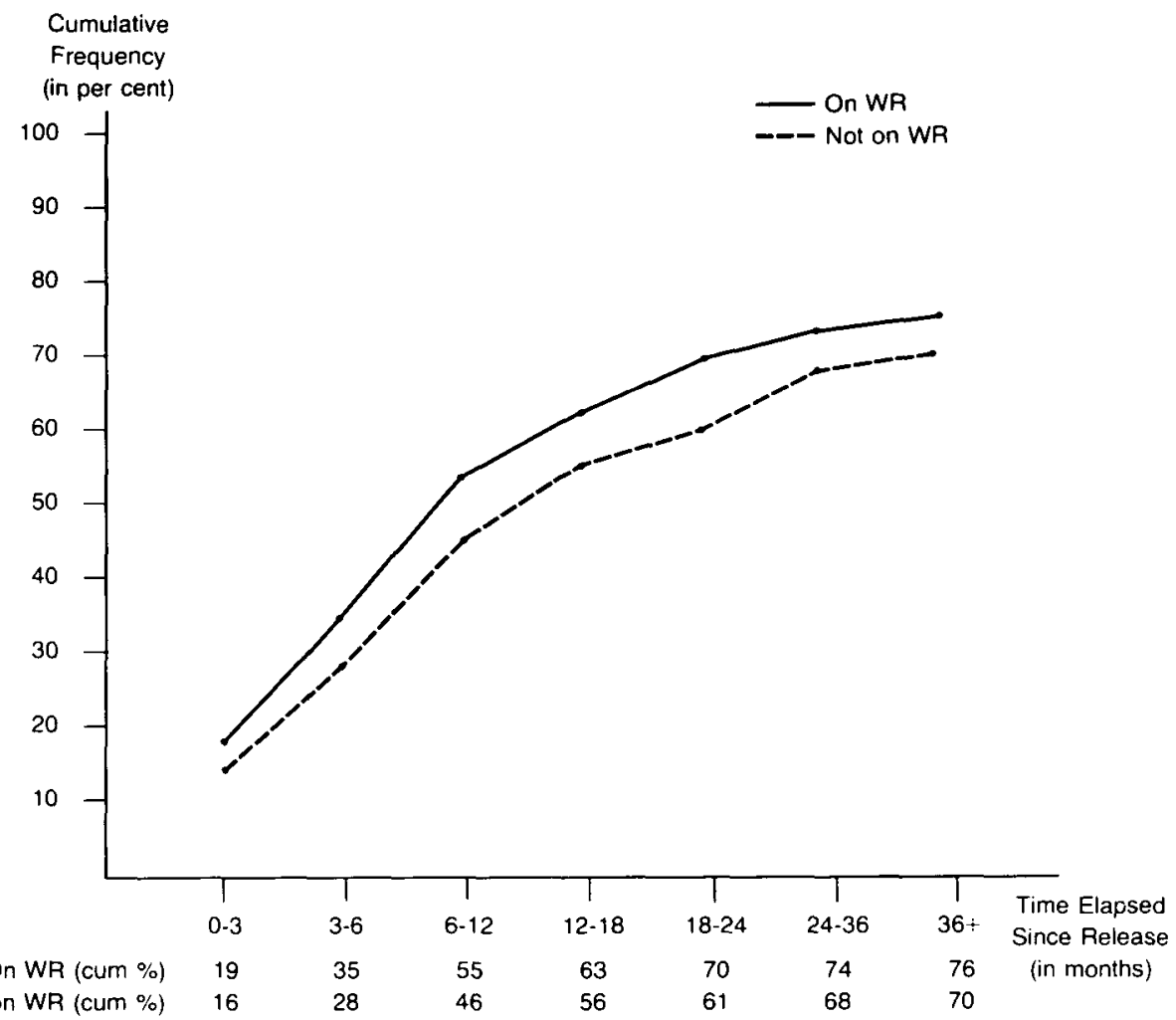

Source: Calculated for this article from the data set used to evaluate the North Carolina work release program. See A. Witte, Work Release in North Carolina: An Evaluation of Iits Post Release Effects (1975).

also convicted of an offense: 76 per cent of the former work releasees and 70 per cent of the men who had not participated in the program. Figures 1 and 2 show that the time of rearrest and reconviction for the two groups were broadly similar.

This dismal conclusion-that the majority of all subjects return to crime and a comparatively greater proportion of former work releases return to crime-brightens somewhat when that class of those studied who received sentences of fifteen days or more is considered. Thirty-one per cent of former work releasees and 34 per cent of those who had not been on the program received such a sentence. As can be seen in Figure 3 , those who were not on the work release program were more likely than work releasees to return to prison during the first twelve months or after two or more years 
FIGURE 3

Cumulative Per Cent Reimprisoned after Various Periods of Time

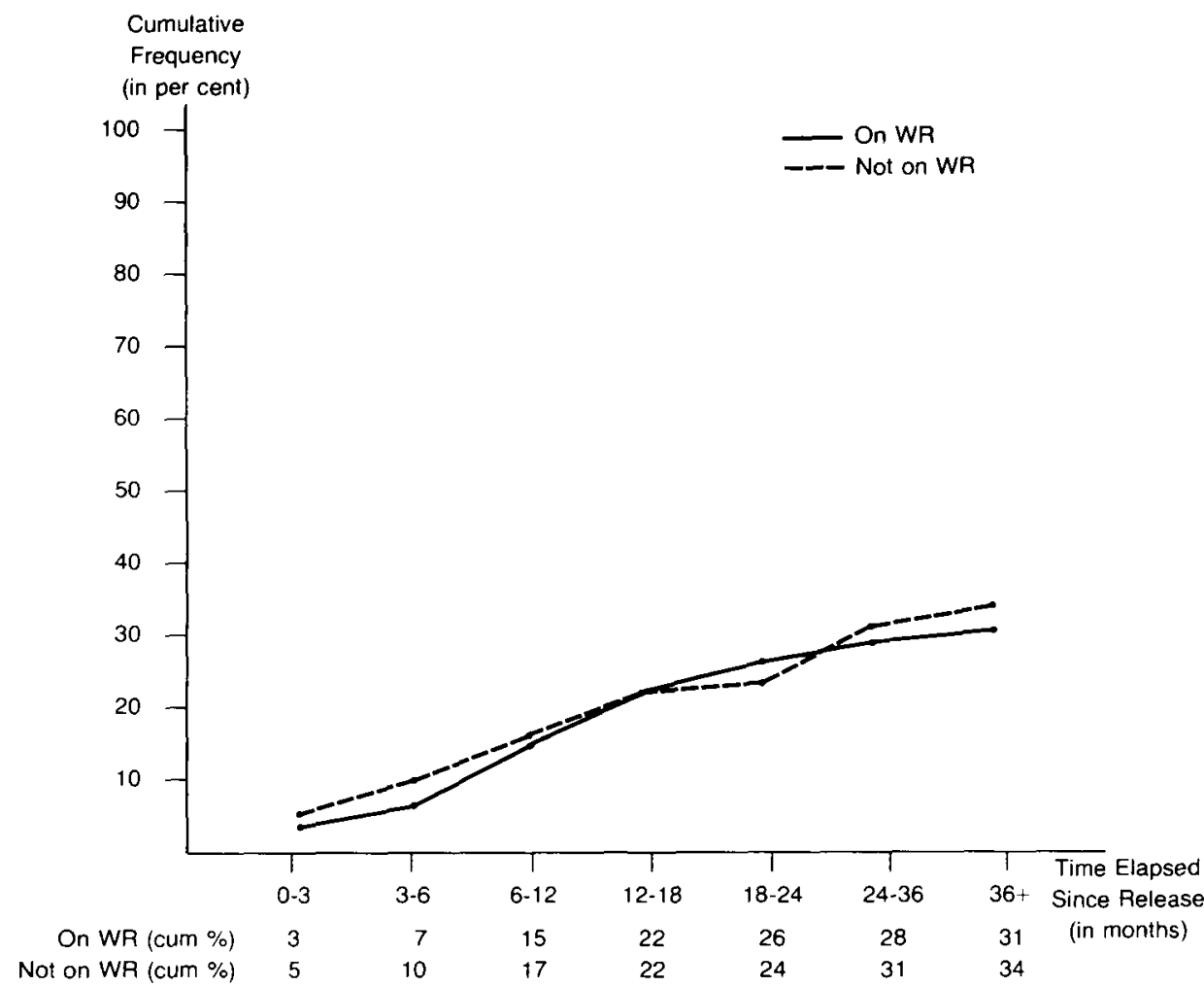

Source: Calculated for this article from the data set used to evaluate the North Carolina work release program. See A. Witte, Work Release in North Carolina: an Evaluation of Its Post Release Effects (1975).

since release. In contrast, work releasees were more likely than non-work releasees to return during their second year after release. From this it would appear that work release aids individuals primarily during the post-release adjustment period.

These figures indicate no significant differences in post-release criminal activity between work releasees and those who had not been on work release. To discover a difference, it is necessary to look more closely at the seriousness of criminal activity. There is a good deal of controversy over the correct "measure of seriousness" of criminal activity. ${ }^{26}$ The measure of seriousness used here is based on classification of offense (misdemeanor or felony) and

26. See Rossi, Waite, Bose, \& Berk, The Seriousness of Crimes: Normative Structure and Individual Difference, 39 Am. Soc. REv. 224 (1974) for a recent attempt to develop a measure and a review of previous attempts. 
length of sentence. It is assumed that a person who is convicted of a felony or who receives a longer sentence is a more serious offender. ${ }^{27}$

Seventeen per cent of the men who did not participate in the work release program were convicted of a felony in the follow-up period, whereas only 8 per cent of the men who did participate were convicted of such an offense. Of the men who were in prison for a felony in 1969 or 1971,6 per cent of the former work releasees and 33 per cent of the men who had not been on the work release program were convicted of a felony in the period during which the project followed their activities. Of those in prison in 1969 or 1971 for a misdemeanor, 8 per cent of the former work releases and 11 per cent of the men who had not been on the program were convicted of a felony during the follow-up period. According to this measure of seriousness, men who had been on the work release program committed less serious offenses after release than did men who had not participated in the program. Indeed, both for ex-misdemeanants and ex-felons considered jointly, and for ex-felons considered separately, these differences are statistically significant. Based on this evidence it appears that work release is a more effective program for felons than for misdemeanants.

In respect to the other measure of seriousness, length of sentence received, former work releasees had an average sentence of five months for the conviction that resulted in imprisonment during the follow-up period; those who had not participated in the program had an average sentence length of thirteen months. The average sentence length received for the most serious offense committed after release was one year, six months for men who had been on work release, and three years, ten months for those who had not been in the program. These differences are statistically significant, and indicate considerable disparity between the groups.

Is this disparity attributable to the one group's participation in the work release program, or to some other characteristic in which the two groups differ? There are in fact a number of significant differences between the two groups. ${ }^{28}$ To determine whether participation in the work release program, in and of itself, affects the seriousness of post-release criminal activity, one must

27. A recent study found that the most generally accepted rating scale for the seriousness of criminal activity (the Sellin-Wolfgang scale) is significantly correlated $(R=.68$ ) with the length of sentence received by North Carolina prison inmates. See L. Shaw, Severity of Crime and Length of Sentence 3 (1976) (N.C. Dep't of Corrections mimeo)

28. Members of the work release group were on the average significantly older when first arrested and when admitted for the term they were serving in 1969 or 1971, had longer sentences in 1969 or 1971 , were more likely to be married and less likely to be first offenders than the non-work release group. The only one of these variables which has been shown to be consistently related to post-release criminal activity is age. Only the difference in marital status and age at first arrest seem to arise directly from the work release selection process. The other differences seem to arise mainly from the fact that younger offenders under the Committed Youth Offender program in North Carolina are more likely to be released under supervision rather than placed on work release if deemed worthy of trust. 
adjust statistically for other factors and determine whether men who participated in the program are still found to commit less serious offenses.

I first adjusted for the seriousness of each man's criminal activity before his incarceration in 1969 or 1971. Each man's performance after release was judged solely in relation to his own performance before sentencing in 1969 or 1971. Under this scheme, the seriousness of the criminal activity of a man who had received an average sentence of five years when convicted before his 1969 or 1971 sentence, and an average sentence of five years when convicted in the follow-up period, would be judged to have undergone no change between the two periods. On the other hand, if he received a seven-year average sentence during the follow-up period, I would judge that the seriousness of his criminal activity increased by two years; if his average sentence was two years, I would judge that the seriousness of his criminal activity decreased by three years.

Men who participated in the work release program decreased the seriousness of their criminal activity, while men who did not participate increased theirs. (See Table III.) Specifically, the average sentence length received by men who had been on the program declined by four months, while the average sentence length for the others increased by five months. In short, men who did not participate in the work release program were worse offenders after their prison experience than they had been before it. In contrast, men who participated in the program not only did not behave worse, they actually behaved better.

But what about the other characteristics, such as age and marital status, in which these two groups differed? A statistical analysis (multiple regression) that adjusted for these other differences still showed that men who had participated in work release significantly decreased the seriousness of their criminal offenses when compared with men who had not been on the program. Specifically, being on work release meant, on the average and adjusting for other factors, a decline in average sentence length (after sample sentence versus before) of thirteen months when compared to the performance of men who were not on the work release program. Again, it should be emphasized that this positive effect results even when all significant and quantifiable intergroup differences are adjusted. ${ }^{29}$

On the basis of this evidence, it appears that although participation in the work release program does not prevent return to illegal activity, it does decrease the seriousness of illegal activity. What facets or benefits of the work release program were responsible for this improvement?

29. Length of the follow-up period was another factor adjusted for in the multiple regression model. It proved to be not significantly related to change in average sentence, probably because the follow-up period averaged thirty-seven months, and most recidivism occurred within twentyfour months (see Figure 3). 
TABLE III

Difference in Average Seriousness of Crimes Committed

Before and After the Sample Sentence

\begin{tabular}{|c|c|c|}
\hline \multirow[b]{2}{*}{ Change in Average Seriousness } & \multicolumn{2}{|c|}{$\begin{array}{l}\text { Relative Frequency } \\
\text { (percentage) }\end{array}$} \\
\hline & $\begin{array}{l}\text { All Work } \\
\text { Releasees } \\
(n=297)\end{array}$ & $\begin{array}{c}\text { Not on Work } \\
\text { Release } \\
(n=344)\end{array}$ \\
\hline \multicolumn{3}{|l|}{ Improvement } \\
\hline $\begin{array}{l}\text { Average seriousness before exceeds average } \\
\text { seriousness after by three years or more }\end{array}$ & 5 & 5 \\
\hline $\begin{array}{l}\text { Average seriousness before exceeds average } \\
\text { seriousness after by one year to two years, } \\
\text { eleven months }\end{array}$ & 18 & 9 \\
\hline $\begin{array}{l}\text { Average seriousness before exceeds average } \\
\text { seriousness after by less than a year }\end{array}$ & 24 & 22 \\
\hline No Difference & 34 & 41 \\
\hline $\begin{array}{l}\text { Deterioration } \\
\text { Average seriousness after exceeds average } \\
\text { seriousness before by less than a year }\end{array}$ & 13 & 10 \\
\hline $\begin{array}{l}\text { Average seriousness after exceeds average } \\
\text { seriousness before by one year to two years, } \\
\text { eleven months }\end{array}$ & 3 & 6 \\
\hline \multirow[t]{2}{*}{$\begin{array}{l}\text { Average seriousness after exceeds average } \\
\text { seriousness before by three years or more }\end{array}$} & 3 & 7 \\
\hline & 100 & 100 \\
\hline \multicolumn{3}{|l|}{ Mean (negative indicates decrease in } \\
\hline Standard deviation: & 27.58 & 50.04 \\
\hline \multicolumn{3}{|c|}{ Test for Difference between Means } \\
\hline vs. non-work releasees: $t=$ & & \\
\hline
\end{tabular}

* Statistically significant at the five per cent level $(\alpha=.05)$.

Source: A. Witte, Work Release in North Carolina: An Evaluation of Its Post Release EFFECTS 46 (1975).

\section{B. Opportunity Changes}

As noted above, participation in the work release program offers a number of benefits. These benefits can be expected to change the opportunities available to a former work-release participant after release. Changed opportunity may be measured both objectively, by comparing the situation of men who participated in work release with the situation of those who did not, and subjectively, by asking work releasees whether they feel that their participation in the program changed the situation they faced on release. 
Objectively, after release men who had been on work release had more stable job records, significantly lower unemployment rates, and higher wages than those who had not participated in the program. Such between-group differences in labor market performance were not apparent before incarceration. Subjectively, 16 per cent of the men who had been in the program said that it helped them after release by providing a job reference, and 25 per cent said that the work experience they gained while on work release helped them after release.

Those who had been on work release did not experience significantly greater family stability than did members of the control group. However, they did feel that the opportunity to support their dependents while in prison was a major benefit of the program.

The work release program does not seem particularly effective in providing participants with new skills, but apparently it does prevent a decline in the skill level of the first job after release. The skill level of the first job after release for work releasees was only marginally higher than the skill level of the job they had before going to prison. However, the skill level of the first job after release for this group was significantly higher than the skill level of the first job obtained by the other subjects. Perhaps this difference results from the fact that men who did not participate in work release are, as noted above, in a dire financial situation and sometimes must accept the first job they can find. In spite of the low level of skill required by most work release jobs, 38 per cent of the men who were on work release claimed to have acquired new job skills while on the program. However, largely because work release jobs are often in different occupations and industries than the jobs these men obtain after release, only 60 per cent of these men claimed to have been able to use these skills since release from prison.

Participation in the work release program seems to ease adjustment after release from prison. The program provided a job at release for 39 per cent of the participants. Largely because of this result, releasees on the average obtained their first post-release job twice as fast as men who had not been on the program (ten versus twenty days).

The effect of the accumulated savings on post-release behavior is rather interesting. The immediate effect appears to be early but relatively minor trouble. Former work releasees were arrested significantly earlier than men who had not been on the program (see Table IV), and the offenses usually involved alcohol (e.g., public drunkenness, driving under the influence, assault on a female). ${ }^{30}$ The joy of release, coupled with the receipt of accumulated work release funds, probably leads to celebration that may get a man in early

30. The assault-on-a-female charges usually consisted of a drunken husband going home and beating up his wife. 
trouble. But the overall effect of those funds seems to be positive: men with a greater number of months on work release, and therefore with more accumulated funds, tend to be less serious offenders than men with fewer or no months in the program. In a previous report it has been estimated that on the average and adjusting for other significant factors, an extra month on work release leads to a one month decrease in average time sentenced during the follow-up period compared to average time sentenced prior to the sample sentence. $^{31}$

TABLE IV

LeNGth of Time UNTIL First Arrest After

Release from Sample Sentence

\begin{tabular}{|c|c|c|}
\hline \multirow[b]{2}{*}{$\begin{array}{l}\text { Length of Time } \\
\text { (in months) }\end{array}$} & \multicolumn{2}{|c|}{$\begin{array}{c}\text { Relative Frequency } \\
\text { (percentage) }\end{array}$} \\
\hline & $\begin{array}{l}\text { All Work } \\
\text { Releasees } \\
(n=244)\end{array}$ & $\begin{array}{c}\text { Not on Work } \\
\text { Release } \\
(n=269)\end{array}$ \\
\hline $0-3$ & 30 & 25 \\
\hline $4-6$ & 22 & 17 \\
\hline $7-9$ & 13 & 15 \\
\hline $10-12$ & 9 & 10 \\
\hline $13-24$ & 21 & 20 \\
\hline $25-36$ & 4 & 9 \\
\hline \multirow[t]{2}{*}{ over 36} & 1 & 4 \\
\hline & $100 \%$ & $100 \%$ \\
\hline Mean: & 8.8 & 11.2 \\
\hline Median: & 6.1 & 8.0 \\
\hline Mode: & 4.0 & 1.0 \\
\hline Standard deviation: & 8.4 & 10.7 \\
\hline \multicolumn{3}{|c|}{$\begin{array}{l}\text { All work releasees vs. non-work releasees: } \\
\qquad 1=2.76^{*}\end{array}$} \\
\hline
\end{tabular}

* Significant at the five per cent level $(\alpha=.05)$.

Source: A. Witte, Work Release in North Carolisa: An Evalceation of lts Post ReLEASE EFFECTS 36 (1975).

Another positive effect of the money earned on work-release is that it eases the pressure to accept the first job that becomes available. Men who participated in the program but did not remain on their work release jobs after prison obtained substantially better jobs than did men who remained on their work release jobs or men who were not in the program. The men who

31. A. WrTte, supra note 23 , at 51 . 
had participated in work release found the money it provided them on release to be its single most important benefit.

The effect of contacts with the free community is very difficult to measure, but work releasees felt such contact to be beneficial. Thirty-three percent of them felt that such contacts eased their adjustment.

Improved attitudes toward oneself and society are difficult to measure objectively, but psychologists have made considerable strides in this area. I measured attitude changes by selecting appropriate scales (Pd, HC, Ma, OI, and ES scales) from the Minnesota Multiphasic Personality Inventory (MMPI). The MMPI was chosen for use because many North Carolina inmates are given this test when they enter the state prison system. By comparing the scores of subjects when they entered prison and when they were interviewed after release, I could discern certain attitude changes.

The results of these tests show that men who have participated in the work release program have attitudes significantly less amoral and antisocial, and demonstrate less hyperactivity than do men who have not been in the program. Such differences in attitudes did not exist when these men entered prison. An examination of the subscales of one test $(\mathrm{Pd})$ indicates that the less antisocial and amoral attitudes of men who have been on work release take the form of a greater ability to accept authority and a greater feeling of selfworth. These are exactly the types of changes that one would expect a program such as work release to encourage.

An improved attitude toward work might also be expected. Although men who were on work release did score lower on the occupation instability scale than men who were not on work release, the difference in mean score between groups is not significant. This lack of significant improvement in attitude toward work may be a reflection of the failure of work release to change significantly the type of jobs that participants pursue after release.

The improved attitudes of former work releasees are probably only indirectly related to their work release experience. It seems likely that much of the change in attitude occurred after release as a result of the changed opportunities these men experienced. In summary, work release seems to change opportunities. These changed opportunities appear to lead directly to decreased criminal activity and to improved attitudes. These improved attitudes may lengthen the beneficial effects of work release or they may lead to an independent decline in criminal activity.

IV

\section{Summary and Conclusions}

This article has described the North Carolina work release program, outlined its benefits, and evaluated its post-release effects. While the program could be markedly strengthened by improving the quality of jobs it offers 
inmates, its benefits are substantial even now both in terms of budgetary savings and post-release performance improvement. The annual financial benefits of work release average more than five per cent of the state correctional budget in North Carolina. The post-release benefits include less serious criminal activity, improved labor market performance, and improved attitudes toward society.

These benefits seem particularly substantial when the limitations of the program are considered. A man with at least one prison conviction, and usually several such convictions, is placed in a job for approximately five months of his latest prison term. The job in which he is placed has significantly lower wages and requires significantly lower skills than either the job he had before incarceration or the job he will have after release. Such low skill jobs provide scant opportunity for skill improvement. Since many of these jobs redirect individuals into industries and occupations which they will leave as soon as they are free to do so, often even the skills that are gained are not utilized after release.

Considering the nature of this work release program, can a major adjustment in life style really be expected? Limited adjustment seems a more reasonable outcome. Indeed, the changes found by this evaluation seem to be surprisingly profound.

There is widespread disenchantment with rehabilitative programs today. Perhaps one reason is that too much is expected from limited programs which are continually understaffed and underfunded. Because of the demands of other, higher priority programs, and because of our ambivalence toward criminals, we usually have made only a perfunctory effort to rehabilitate them. And yet we have expected rehabilitation programs to alter substantially the way these individuals live their lives. Most evaluations of rehabilitative programs to date have used recidivism rates as their principal measure of success. Significant differences in recidivism rates between a participating and nonparticipating group can occur only if a substantial number of the participating group cease to commit illegal acts, i.e., decide to alter (substantially) the way they live their lives. The North Carolina work release program would have been judged "not to work," as so many rehabilitative programs have before it, if judged by this criterion. Like this work release program, however, a number of other rehabilitative programs would have been judged successful if they had been judged by less stringent criteria, such as the seriousness of post-release criminal activity. ${ }^{32}$ It appears that in criminal rehabilitation, as in

32. See, e.g., Taylor, An Evaluation of Group Therapy in a Girls' Borstal, INr'L J. PsychotheraPy 17, 168-77 (1967); C. Jesness, The Fricot Ranch Study: Outcomes with Small Versus Large Living Groups in the Rehabilitation of Delinquents (Oct. 1, 1975) (unpublished Research Report No. 27 with California Youth Authority); 1 \& 2 R. Levinson \& $\mathrm{H}$. Kitchenet, Demonstration Counsel- 
many other social programs, the failure to achieve inflated expectations has led to complete rejection of the possibility of social change.

The evidence reported herein indicates that North Carolina's work release program does improve post-release performance. Recent evaluations of other such programs indicate that while success with work release is not unique to North Carolina it is also not universal. On the one hand, two evaluations of county work release programs in California have shown significantly lower recidivism rates for men who particpated in these programs than for comparable groups who did not. ${ }^{33}$ These results are even more convincing than those reported above. On the other hand, evaluations of the work release programs in Massachusetts ${ }^{34}$ and Florida ${ }^{35}$ have shown no positive post-release effect for participants. The only obvious features in which the programs in North Carolina and California differ from those in Massachusetts and Florida are size and age. The work release programs in North Carolina and California are among the oldest and largest work release programs in the country.

Manpower programs other than work release have been evaluated less extensively. However, a few findings of interest have emerged. Two pretrial intervention projects providing employment-oriented assistance to first offenders show reductions in recidivism in the short- but not the long run. ${ }^{36} \mathrm{Re}$ searchers on a recent project in Baltimore sought to determine what type of opportunity change-job placement services or financial aid-was most effective in reducing recidivism. They found that job placement services had no effect on recidivism but that financial aid significantly reduced the percentage of men convicted of economic crimes (i.e., theft, robbery, burglary, and larceny). ${ }^{37}$

These findings, while certainly not unequivocal, give rise to some hope for the effectiveness of appropriately designed opportunity-changing manpower programs. It would seem wise at least to experiment with this approach further before completely rejecting rehabilitation as a viable objective.

Even if correctional agencies reject rehabilitation in favor of a policy of strict deterrence and incapacitation, they would do well to maintain programs

ing Project (1962-1964) (unpublished document at National Training School for Boys, Washington, D.C.).

33. Jeffery \& Woolpert. Work Furlough as an Alternative to Incarceration: An Assessment of Its Effects on Recidivism and Social Cost. 65 J. CRIM. L. \& C. no. 3, at 405-15 (1974); Rudoff \& Esselstyn, Evaluating Work Furlough: A Followup, 37 Fed. Probation 48-53 (1973).

34. Mass. Dep't of Corrections, An Evaluation of the Impact of the MCL-Concord Day Work Program (1972).

35. Address by C. Waldo \&. T. Chiricos, Evaluating Social Policy: An Empirical Assessment of Work Release, American Sociological Association Meetings (Aug. 27, 1975).

36. R. Taggart, III, The Prison of Unemployment: Manpower Programs for Offenders (1972).

37. U.S. Dep't of Labor, Employment and Tranisg admintsation, Unlocking The Second Gate: The Role of Financial Assistance in Reducing Recidivism among ExPrisoners 45 (1977). 
such as work release which can substantially decrease the extreme costs that will be incurred by such a policy. The price of incarceration today is already high, almost $\$ 2 \frac{1}{2}$ billion in fiscal year 1972 . Despite this level of expenditure, the increasing crime rate, coupled with longer sentences and stricter parole decisions, has led to severe overcrowding in many, if not most, correctional systems. That this level of overcrowding is not likely to be long tolerated by the federal judiciary is indicated by the fact that at least five states-Arkansas, Alabama, Florida, Louisiana, and Mississippi-are under some form of court order to relieve overcrowding. ${ }^{38}$ Even if such overcrowding is allowed to continue, and even if no increase in security costs at correctional facilities results from the new policy (which seems unlikely), the cost per inmate will remain, at a bare minimum, $\$ 5,000$ per year served. It seems unlikely that the public in its present mood of financial conservatism will be willing to bear the expense of such an arrangement unless these costs are mitigated somewhat by such programs as work release.

In conclusion, I would like to suggest that programs such as work release should be continued under any correctional philosophy which accepts the existence of prisons. If a correctional philosophy emerges which has greater emphasis on incapacitation and deterrence but maintains proven rehabilitative programs, work release can be justified because it improves post release behavior without significantly reducing incapacitation or deterrence. If a philosophy of strict deterrence and incapacitation emerges, work release can be justified because it decreases the cost of such a philosophy without substantially mitigating its effects.

38. N.Y. Times, Jan. 25, 1976, at 1, col. 4. 